\title{
The Research of Supply Chain Information Management of Internet of Things about Agricultural Products Based on RFID and EPC
}

\author{
Guogang $\mathrm{Li}^{\mathrm{a}}$, Jiaying Zhou ${ }^{\mathrm{b}}$ and Ting Yang ${ }^{\mathrm{c}}$ \\ School of Management, Tianjin University of Technology, Tianjin 300384, China \\ amonsteryz@163.com, bzjywanx@163.com, 578478183@qq.com
}

Keywords:IOT, RFID, information management.

\begin{abstract}
With the rapid development of Internet of things technology, the supply chain of agricultural products is increasing maturity in the Internet of things environment. Agricultural products supply chain in our country is in a key period from traditional mode to a modern one. This article finds out the combination point between agricultural products supply chain each link with the Internet of things, and analyzes information processing system of the agricultural supply chain under the Internet of things technology based on Internet of things technology and the characteristics of the agricultural products supply chain management, having guidance value to implementing agricultural information sharing in the IOT environment in the future.
\end{abstract}

\section{Introduction}

With the rapid development of science and technology, information technology has penetrated into all fields of national economy and social development. Research of Internet of things has been becoming the hot spot currently.

Iot is widely applied in green agriculture, environmental monitoring, logistics monitoring, remote medical treatment and other fields, and radio frequency identification technology has a unique identifier, wireless transmission, moisture resistant, strong durability and other technical advantages. Using high-tech means of information technology to achieve the overall supervision , tracking, and tracing of the security situation agricultural products controlling agricultural products from the source, helping coordinate and solve safety problem of agricultural products.

\section{Theory Overview}

\subsection{IOTtechnology}

Internet of Things (IOT), also known as "sensor network" refers to using information through a variety of sensor devices, such as sensors, RFID, global positioning systems, infrared sensors, laser scanners, and other gas sensors Such devices and technology, real-time collects anything or process which need to monitor, access, interactive objects, collecting the information of its sound, light, heat, electricity, mechanics, chemistry, biology, location, etc. to form a giant of the Internet network.IOT are called the third wave of world information industry. following the computer and the Interne.IOT has three characteristics: overall perception; reliable delivery; intelligent processing.

\subsection{The architecture of IOT}

At present, the domestic and foreign scholars generally can be divide architecture of Internet of things into three layers: the sensing layer, network layer and application layer.

Sensing layer mainly includes RFID/EPC labels, speaking, reading and writing, sensors, sensor network, intelligent terminal, access gateway, etc. Sensing layer is mainly used to identify objects, collect information, and passes out the collected information. The network layer is mainly used for transmission of information, including the Internet, mobile communication network, a satellite communications network. Application layer is the interface to user and the Internet including some industrial applications of transmitting information on the network layer, including smart home, smart healthcare, smart cities, intelligent environment, intelligent transportation, intelligent justice, intelligent agriculture, intelligent logistics applications. 


\subsection{Supply chain structure of agricultural products}

Agricultural supply chain is to meet consumer demand and achieve the value of agricultural produce through controlling the information flow, logistics and cash flow, performing physical entities and related information from the producers of agricultural products to the physical nature of economic activities of consumers, which is a whole functional chain network structure contents the farmers producers, intermediaries, suppliers, processors, distributors, retailers and consumers. In general, the agricultural products supply chain is composed of four links: the means of production supply chain, production, processing and sales. Elements enterprise of the agricultural products supply chain includes production breeding, processing and sales enterprise, logistics enterprise, whose management pattern as shown.

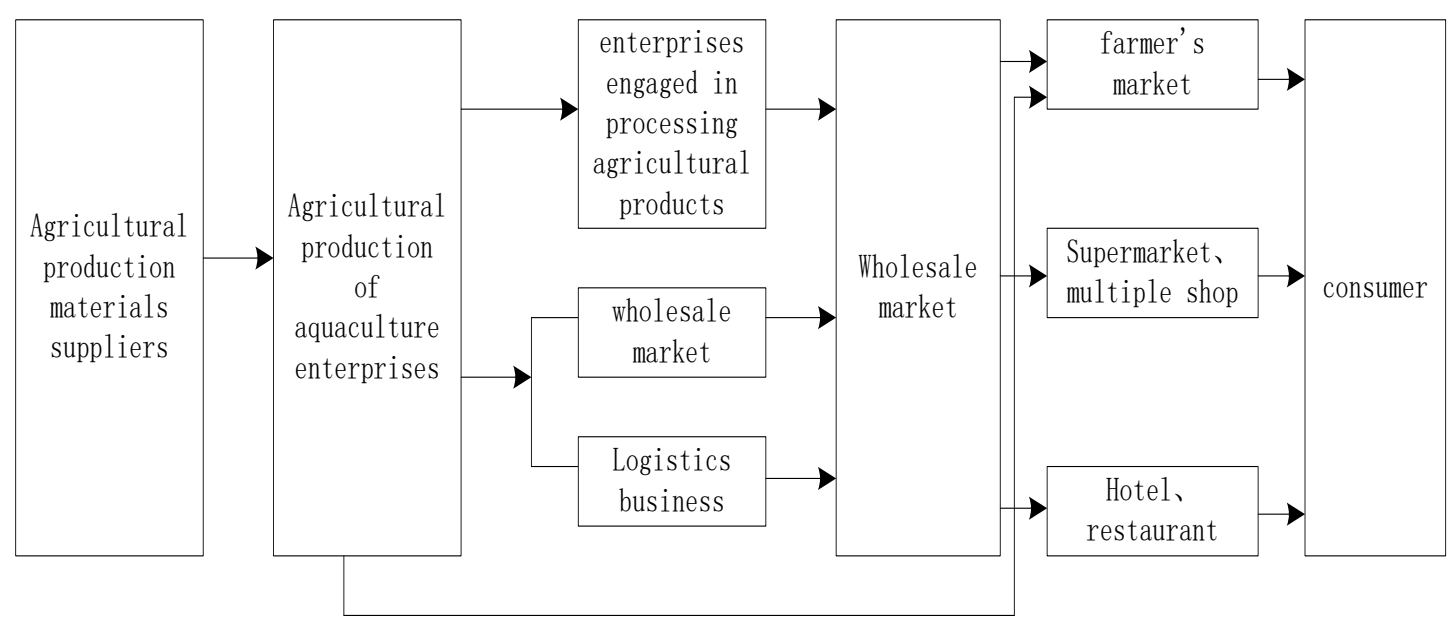

Fig. 1 The mode of traditional agricultural products supply chain management

\section{IOT in the application of the agricultural products supply chain}

\section{1 integration point of IOT technology and agricultural supply chain}

The Internet of things based on intelligent computing platform, the core technology of which is cloud computing intelligence. Internet of things technology based on Intelligent computing platform can perfect combines and the agricultural products supply chain management. The whole agricultural Internet of things can be divided into three levels: basic perception layer, network layer and application layer. Agricultural supply chain in the IOT environment is based on the traditional agricultural supply chains, converging networking technology features, to achieve safe production of agricultural products, real-time monitoring, information sharing and other market participants.

Things layer for agricultural products from the base to the supermarket, feedback the air, water, temperature, pesticides, fertilizers, insects and other information during the product and real-time information in logistics process and supermarket by signing sensor devices and video, in agricultural base, the identification tag of product, logistic vehicles, through effective wired or wireless network in real-time, timely and effectively ensuring quality of agricultural products from the base to the consumer through all aspects of the physical layer data server and real-time monitoring platform of application layer.

\subsection{The agricultural products logistics information tracking in the IOT environment}

In agricultural farming production, each agricultural individuals is equipped with corresponding EPC coding RFID electronic tag. When agricultural products enter the next step, the health and quarantine departments will check safety and quarantine of agricultural products , the qualified ones enter into the next circulation (in poultry products, for example, entering the slaughter and processing sectors), and according to the information of the health and quarantine departments do record about the batch of quarantine. Quarantine records will form a new PML files associated with quality information of agricultural farming areas, and in this form is stored on the farm breeding production enterprise EPCIS (also known as PML server), as the individual initial file. When agricultural products in the form of individual outbound, through the RFID on the rf read equipment start 
electronic tag on the packing and read the tag information, and through the radio frequency devices connected to local ALE system, will make the quality change and the actual change of the production match with the corresponding PML file information, and pass the collected information to local ALE system, then the ALE through relevant processing, will identify the relevant information of agricultural products in the record to the local EPCIS.

At the same time, the EPC code and the server address are registered in the local ONS server, make it be the relationship in the ONS, such ONS makes EPC code of each agricultural product and agricultural products information EPCIS address match. The local EPC information server will register also dynamic information of production in EPC Discovery Services. The information processing of agricultural products supply chain is shown in figure 2.

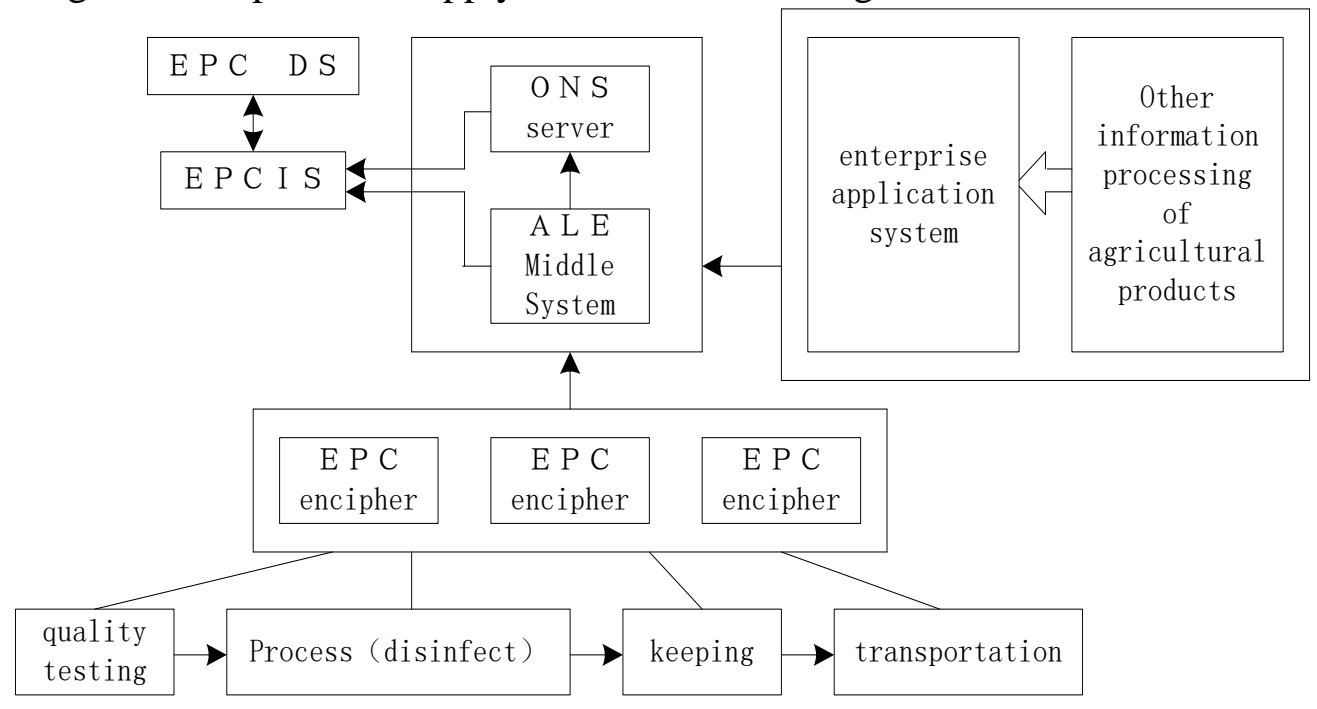

Fig. 2 information processing of agricultural supply chain

In the circulation of supply chain, if the reader read EPC information of production, RFID radio frequency readers will collect it to the EPC of production and pass it to local network layer ALE after filtering submitted to the enterprise application to handle. after the RFID reader accessed the tag's EPC code (or sensor information). Enterprise applications based on the actual situation, pass the ALE information to the local ONS system, which has responsibility for this EPC code corresponds to query this automatically to find stored items in the URL address for product information and update the information (such as the impact factors about agricultural product quality and shelf life, storage humidity and temperature and other information

Application software can update the local information about agricultural products again, such as the location ,the time of the current shelf life and destination, etc., and automatically send shipping alert before the expiration date. RFID read device will record dynamic information of production to the local EPC information server, at the same time, the local EPC information server will also register the dynamic information in the EPC server (EPC Discovery Services). When agricultural information were recorded to the local EPC information server, ALE register agricultural production information to ONS, and then through the object name resolution server drug information can be converted to physical markup language (PML), to produce the corresponding PML file store in the EPCIS. In addition, all information on the Internet of things (such as the basic characteristics of the productions, belongs to the related data) are in physical markup language (PML) file format to transmit, PML file may also include some of the real-time information, sensors, etc.

\section{Summary}

the Internet of things technology make the agricultural products supply chain structure optimistic integrate, and create a security intelligence high yield and benefit agricultural products supply chain. As the government and relevant enterprises attach great importance to the development of IOT technology, as well as the technology continues to mature, and the deepening of the relevant 
theoretical research, IOT will play a positive role on the future development of the supply chain, and be more and more applied.

\section{References}

[1] Ye Huang. The research of agricultural products supply chain information sharingBased on livestock. Guangzhou: south China university of technology,2010, p.23-26.

[2] Yong-xiang wu. the research of present situation and development prospect of Radio frequency identification technology [J]. Microcomputer information, Vol.22(2006),p.234-236

[3] Jian-Wei Li. the optimization of agricultural products supply chain Under the background of the Internet of things [J]. Journal of henan agricultural science Vol.40(2011), p.10-12.

[4] Bo Yan. The analysis of influence factors of Internet of things technology adopted in the agricultural products supply chain. Journal of soft science. Vol.27(2013) p.22 -26.

[5] The research of design and application of EPC network information service: Huazhong university of science and technology, p.56-59. 